\title{
Biological Control of Adult Populations of Grape Phylloxera with Enthomopathogenic Fungus
}

\author{
Lidia FICIU ${ }^{1 *}$, Elena BRINDUSE ${ }^{1)}$ Marian ION ${ }^{11}$ \\ ${ }^{1}$ Research and Development Institute for Viticulture and Enology, Valea Calugareasca,Valea Mantei \\ street, no. 1, Valea Calugareasca, zipe code 107620, Prahova, Romania; \\ ${ }^{*}$ corresponding author, e-mail: ficiulidia@yahoo.com
}

BulletinUASVM Horticulture 72(1) / 2015

Print ISSN 1843-5254, Electronic ISSN 1843-5394

DOI:10.15835/buasvmcn-hort:10746

\begin{abstract}
In order to analyze the efficacy of the 4 types of fungus preparation based on the Beauveria bassiana spores on the adult populations of grape phylloxera an experiment arranged in a randomized complete block design with three replications was organized in the greenhouse conditions. There were taken into study two grapevine varieties, Cabernet Sauvignon and Feteasca alba. The efficiency of bioproducs was determined based on the results regarding the period of the persistence and the viability of conidia on the leaves after the treatments, the period of the virulence of bioinsecticides and their insecticidal capacity. The conidia of Beauveria bassiana persisted on the leaves surface and infected the larvae and adults of phylloxera for a period of minimum six days, depending of the bioinsecticide composition. The chemical insecticides caused a stronger and faster lethality in comparison with the fungal biopreparations, the high larval mortality of $90.7 \%$ being recorded during the first two days from the treatment. After six days, the rate of lethality caused by the variant of bioinsecticide represented by conidial suspension added with $1 \%$ glycerol and $1 \%$ canola oil was similar to that produced by chemical preparation. Repeated application of the bioinsecticides based on the Beauveria bassiana can cause a significant reduction of the Phylloxera population and it could replace the chemical treatment.
\end{abstract}

Keywords: Beauveria bassiana, bioinsecticide, grape phylloxera.

\section{INTRODUCTION}

Phylloxera (Phylloxera vastatrix) is considered the most important pest of vineyards worldwide. One of the mosteffective ways to control the damage is based on the use of the Beauveria bassiana entomopathogenic fungus biopreparation (Daoust and Pereira, 1986).

The entomopathogenic fungus, Beauveria bassiana (Balsamo) Vuillemin, has shown potential for the management of insects (Feng et al. 1994) and its pathogenicity has been demonstrated in a field environment against insect populations, belonging to various orders: Coleoptera (Liuel Bauer, 2008, Todorova el al., 1996; Todorova et al., 2002), Homoptere (Dara et al., 2007), Lepidoptera (Nguyen et al., 2007) and hemiptere (McGuire et Leland, 2006).
In order to be used as biocontrol agents, the conidia, which are the main component of the bioinsecticides based on Beauveria bassiana have to be stable (Sabbahi et al., 2008).

There are very few reports concerning the persistence of the Beauveria bassiana conidia on the leaves under natural conditions and also, regarding the efficacy of the products based on Beauveria bassiana on the adult populations of Phylloxera vastatrix, under controlled conditions, in the greenhouse and field.

The present study aimed to establish the optimum composition of the bioinsecticid that could determine the maintaining of the viability of conidia for a longer period of time while maintaining their virulence ability for reducing of phylloxera population. 


\section{MATERIALS AND METHODS}

A conditioning liquid product of Beauveria bassiana with fungitoxic effect was used in the biological control. The studies concerning the efficiency of the bioproducs based on Beauveria bassiana on the grape phylloxera (Dactylosphaera vitifoliae) populations were achieved in the greenhouse conditions using Cabernet Sauvignon and Feteasca alba as biological material.

The efficiency of bioproducs was determined based on the results regarding the period of the persistence and the viability of conidia on the leaves after the treatments, the period of the virulence of bioinsecticides and their insecticidal capacity.

The data were compared with those recorded in the case of the chemical treatments.

An experience with 3 factors, using the method of subdivided plots was performed. 16 experimental variants were afforded:

Factor A: the variety with two graduations $(\mathrm{a}=2)$ :

$\mathrm{a}_{1}$ - Cabernet Sauvignon;

$\mathrm{a}_{2}$ - Fetească albă.

Factor B: conidial concentration, with two graduations $(b=2)$ :

$\mathrm{b}_{1}-2,5 \times 10^{7} / \mathrm{ml}$;

$\mathrm{b}_{2}-3,2 \times 10^{9} / \mathrm{ml}$.

Factor C: the type of fungal formulation, with four graduations $(c=4)$ :

$\mathrm{c}_{1}$ - conidial suspension in Coral modified liquid medium; $\mathrm{c}_{2}$ - conidial suspension added with $1 \%$ glycerol; $\mathrm{c}_{3}$ - conidial suspension added with $1 \%$ glycerol; $1 \%$ canola oil;

$\mathrm{c}_{4}$ - conidial suspension added with $1 \%$ glycerol;

$1 \%$ canola oil and $0,5 \%$ clay.

The treatments were performed in the greenhouse conditions, in open space. A hand sprayer with flow rate of two liters was used to carry out the treatments. The treatments were performed in the morning, in order to limit the unwanted effects caused by UV radiation.

Aspects concerning the organization of the experimental device are presented in Fig.1.

The persistence of the insecticidal activity and viability of the conidia were performed by analysis of leaves after the treatment. Six leaves for each experimental variant were collected every three days, for nine days. Three leaves were used to determine the period of virulence of bioinsecticides, and three days for establishing the degree of the conidia viability.

Evaluation of the duration of insecticidal activity of the preparations based on Beauveria bassiana on the grape phylloxera population was performed every two days after treatments.

Three leaves per each variant were placed in the Petri dish on filter paper moistened with sterile distilled water. Leaf petiole was kept in a bowl of water in order to maintain the leaf turgensy. Each leaf was infested with 20 larvae

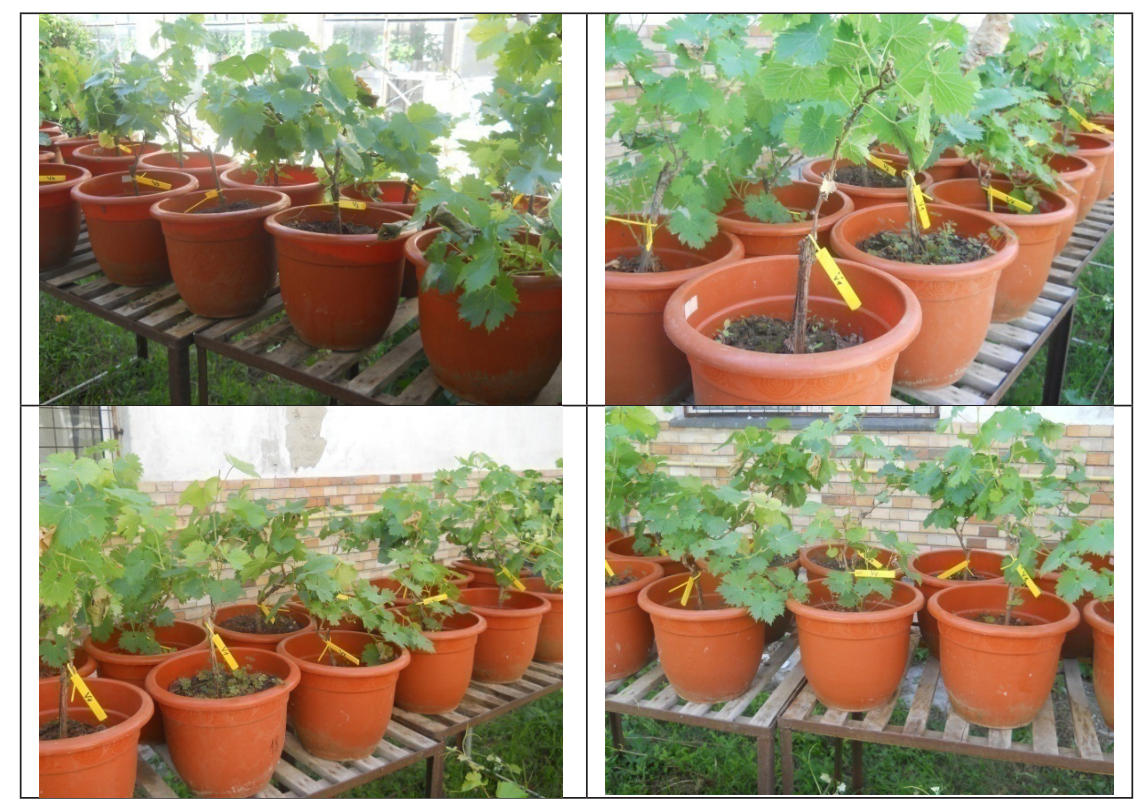

Fig. 1. Aspects concerning the organization of the experimental device 
of grape phylloxera. Microscopic observations on larval mortality were made for six days. True mortality was taken to occur for those cadavers on which sporulation were visible.

The mortality assay was calculated according to the Abbot's Mortality corrected \% using formula:

Abbot's Mortality corrected $\%=(1-\mathrm{n}$ in $\mathrm{T}$ after treatment/n in Co after treatment) x 100 .

where: $\mathrm{n}=$ number of live insects, $\mathrm{T}=$ treated, Co = control.

\section{RESULTS AND DISCUSSION CONIDIA VIABILITY}

A significantly decrease in the number of conidia on the leaves, during the time was put into evidence.

The highest number of conidia reported to the leaf area was recorded after two days of the treatment. The values ranged between $56.0 \times 10^{3}$ $\mathrm{CFU} / \mathrm{cm}^{2}$ (conidial suspension in Coral modified liquid medium) and $83.3 \times 10^{3} \mathrm{CFU} / \mathrm{cm}^{2}$ (conidial suspension added with $1 \%$ glycerol; $1 \%$ canola oil) considering the application of the bioinsecticides in concentration of $2.5 \times 10^{7} \mathrm{CFU} / \mathrm{ml}$ and between $58.3 \times 10^{3} \mathrm{CFU} / \mathrm{cm}^{2}$ (conidial suspension in Coral modified liquid medium) and $85.3 \times 10^{3} \mathrm{CFU} / \mathrm{cm}^{2}$ (conidial suspension added with 1\% glycerol; 1\% canola oil and $0,5 \%$ clay) in case of the application of the bioinsecticides in concentration of $3.2 \times 10^{9}$ $\mathrm{CFU} / \mathrm{ml}$.

After 6 days of treatment, the number of conidia decreased up to $97.6 \%$ in case if the application of the bioinsecticides in concentration of $2.5 \times 10^{7}$ conidia/ml and up to $98.3 \%$ at the concentration of $3.2 \times 10^{9}$ conidia/ml (Fig. 2).

The analysis of variance concerning the conidia viability after the first day of treatment, for the whole experience, indicated a lack of statistical significance in the case of the simple action of Factor A (variety), and Factor B (concentration of bioinsecticide) and the presence of the significance for factor C (compositionof bioinsecticide) (Fig.1.).

The effect of these reactions partially extended on the binary interactions involving Factor A (A $\mathrm{x} B$ ) and (A x B x C) which have not statistically significance.

The existence of statistical significance for factor $C$ and binary interactions between factors $B$ $\mathrm{x} C$ indicates the great influence exercised by these two factors from the first day of treatment.

The analysis of variance concerning the conidia viability after six days of treatment indicated a lack of statistical significance in the case of the simple action of Factor A (variety), and of combined action A x B, the presence of an weak statistical significance for Factor B (concentration of bioinsecticide) and the maintaining of the presence of the significance for factor $\mathrm{C}$

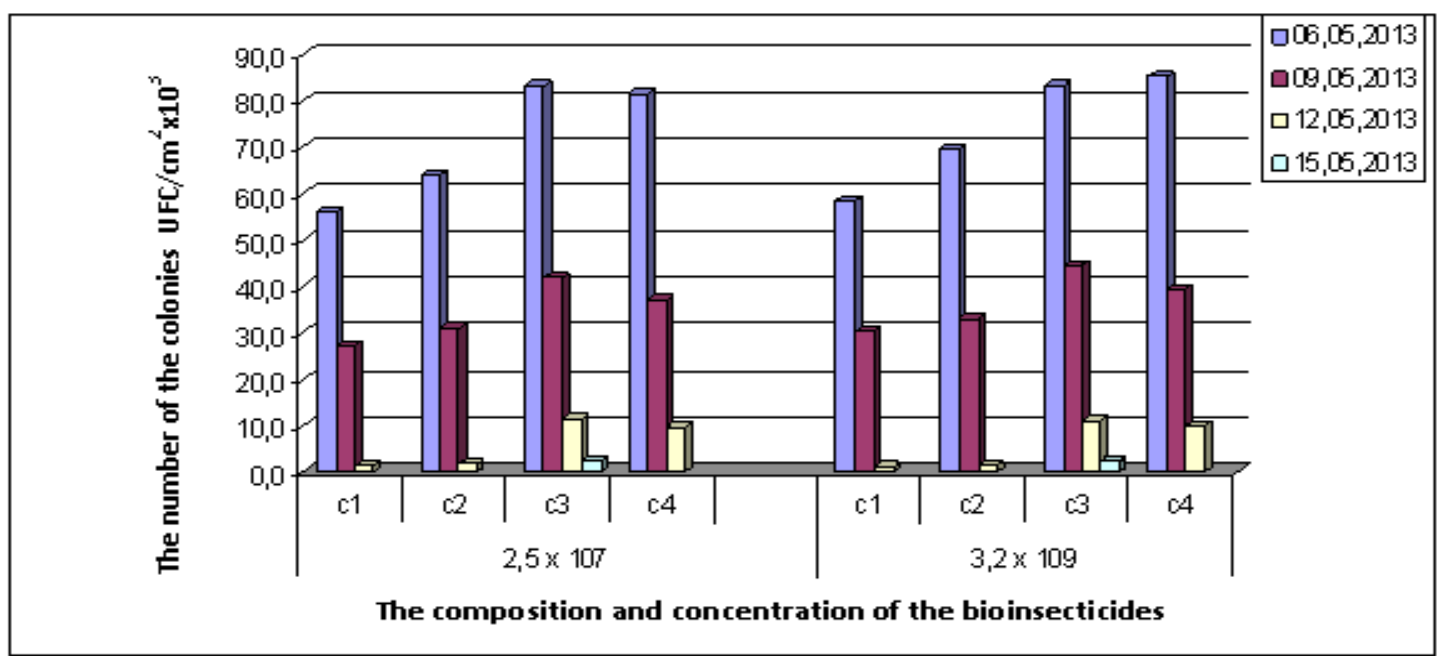

Note: $c_{1}$ - conidial suspension in Coral modified liquid medium; $c_{2}-$ conidial suspension added with $1 \%$ glycerol; $c_{3}-$ conidial suspension added with $1 \%$ glycerol; $1 \%$ canola oil; $\mathrm{c}_{4}$ - conidial suspension added with $1 \%$ glycerol; $1 \%$ canola oil and $0,5 \%$ clay.

Fig. 2. Evolution of the conidia viability related to the composition and concentration of bioinsecticide 
Tab.1. Analysis of variance regarding the viability of the conidia after the first day of the treatment

\begin{tabular}{|c|c|c|c|c|c|c|c|c|c|}
\hline \multirow[b]{2}{*}{ Cause of variability } & \multirow{2}{*}{ SP } & \multirow{2}{*}{ GL } & \multirow{2}{*}{$\mathrm{s}^{2}$} & \multirow[b]{2}{*}{$\mathrm{S}_{\mathrm{d}}$} & \multicolumn{2}{|c|}{ F Probe } & \multicolumn{3}{|c|}{ t-Test } \\
\hline & & & & & $0.5 \%$ & $1 \%$ & $5.0 \%$ & $1.0 \%$ & $0.1 \%$ \\
\hline \multicolumn{10}{|l|}{ The variability of large plots } \\
\hline SP large plots & 1.34 & 5 & 0.27 & & & & & & \\
\hline SPR & 1.33 & 2 & 0.67 & & 18.51 & 98.5 & 4.3 & \multicolumn{2}{|c|}{9.93} \\
\hline SPA (A- Variety) & 0.003 & 1 & 0.003 & 0.011 & 2.29 & & 0.05 & 0.11 & 0.35 \\
\hline SP Error (a) & 0.003 & 2 & 0.001 & & & & & & \\
\hline \multicolumn{10}{|l|}{ Variability of medium plots } \\
\hline SP large and medium plots & 3.51 & & & & & & & & \\
\hline SP medium plots & 2.18 & 6 & 0.36 & & 7.71 & 21.2 & 2.78 & 4.6 & 8.61 \\
\hline $\begin{array}{l}\text { SPB (B - Concentration of } \\
\text { bioinsecticide) }\end{array}$ & 0.56 & 1 & 0.56 & 0.176 & 1.51 & & 0.49 & 0.81 & 1.52 \\
\hline SP combination AxB & 0.69 & & & & 7.71 & 21.2 & & & \\
\hline SP AxB & 0.12 & 1 & 0.12 & 0.249 & 0.32 & & 0.69 & 1.15 & 2.15 \\
\hline SP Errors (b) & 1.49 & 4 & 0.37 & & & & & & \\
\hline \multicolumn{10}{|l|}{ Variability of small plots } \\
\hline SPT & 67.2 & & & & & & & & \\
\hline SP small plots & 63.7 & 36 & 1.77 & & 3.01 & 4.72 & 2.06 & 2.8 & 3.75 \\
\hline $\begin{array}{l}\text { SPC (C- Compozition of } \\
\text { bioinsecticide) }\end{array}$ & 61.6 & 3 & 20.52 & 0.097 & $365^{* *}$ & & 0.20 & 0.27 & 0.36 \\
\hline SP combination $\mathrm{AxC}$ & 61.6 & & & & 3.01 & 4.72 & & & \\
\hline SPAxC & 0.1 & 3 & 0.02 & 0.137 & 0.38 & & 0.28 & 0.38 & 0.51 \\
\hline SP combination $\mathrm{B} \times \mathrm{C}$ & 62.8 & & & & 3.01 & 4.72 & & & \\
\hline SP B xC & 0.7 & 3 & 0.23 & 0.137 & $4.015^{*}$ & & 0.28 & 0.38 & 0.51 \\
\hline SP combination abc & 63.1 & & & & 3.01 & 4.72 & & & \\
\hline SP A x B x C & 0.1 & 3 & 0.02 & 0.194 & 0.396 & & 0.40 & 0.54 & 0.73 \\
\hline SP Error (c) & 1.3 & 24 & 0.06 & & & & & & \\
\hline
\end{tabular}

(composition of bioinsecticide) and for binary $(\mathrm{Ax}$ $\mathrm{C}$; $\mathrm{B} \times \mathrm{C})$ and ternary $(\mathrm{A} \times \mathrm{B} \times \mathrm{C})$ interactions.

The two vinifera varieties, Cabernet Sauvignon, and Feteasca alba had a similar reaction to the same concentration of about bioinsecticides, this aspect being maintained throughout the duration of the experience as evident from analysis of variance which put into evidence that the variety (Factor A) is not a significant factor influencing the viability of conidia.

The simple action of factor C (mean C) after 6 days of treatment remained very significant compared with the average of the experience. The simple conidial suspension without protection, in Coral liquid medium and that with the addition of $1 \%$ glycerol induced significant differences in a negative way, the conidia viability being with
$67.47 \%$ and $60.24 \%$ respectively lower than the mean of experience.

The other two variants, conidial suspension added with $1 \%$ glycerol; $1 \%$ canola oil $\left(\mathrm{c}_{3}\right)$ and conidial suspension added with $1 \%$ glycerol; $1 \%$ canola oil and $0.5 \%$ clay $\left(\mathrm{c}_{4}\right)$ caused significant differences in a positive way, the conidia viability being higher with $39.76 \%$, and $26.51 \%$ respectively.

The comparison between these last two variants showed a greater efficacy with $9.48 \%$ of the variant $\mathrm{c}_{3}$.

Compared with the mean of experience, regarding Cabernet Sauvignon variety a lower viability of conidia with $60.49 \%$, respectively with $48.15 \%$ was registered for the types of $c_{1}$ (conidial suspension in Coral modified liquid medium) and $\mathrm{C}_{2}$ (conidial suspension added with $1 \%$ glycerol) 
formulations and with $81.48 \%$, respectively with $29.63 \%$ higher for $\mathrm{c}_{3}$ (conidial suspension added with $1 \%$ glycerol; $1 \%$ canola oil) and $\mathrm{c}_{4}$ (conidial suspension added with $1 \%$ glycerol; $1 \%$ canola oil and $0.5 \%$ clay) formulations .

Concerning Feteasca alba variety, a similar response was observed but the differences from the mean are much higher (Fig. 3).

Establishing the period of the virulence of the bioinsecticides

A decrease of the insecticidal activity of the formulations based on Beauveria bassiana was registered depending of the treatment time. After two days from the treatment, a lethality rate between $11.7 \%$ and $21.7 \%$ at the concentration of $2.5 \times 10^{7}$ conidia/ml and double at the concentration of $3.2 \times 10^{9}$ conidia/ml was recorded.

After 6 days from the treatment the rate of lethality increased up to $70 \%$ in case of $2.5 \times 10^{7}$ conidia/ml and up to $94.7 \%$ at the concentration of $3.2 \times 10^{9}$ conidia $/ \mathrm{ml}$. The chemical insecticides can determined a more intense and rapid lethality in comparison with the fungal biopreparations, $88.3 \%$ on average after two days and $95 \%$ after four days of treatments (Fig. 4).

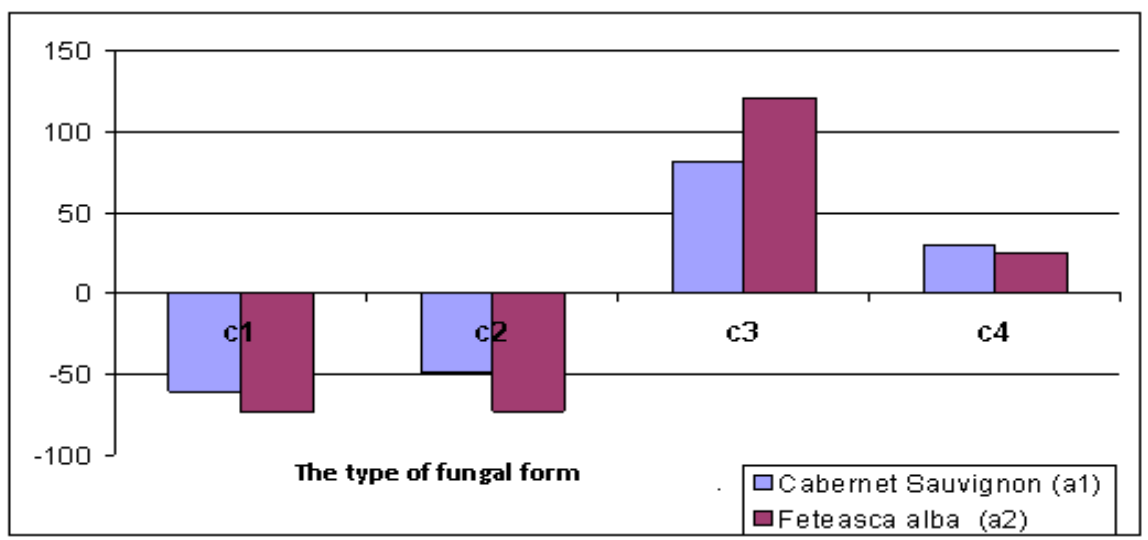

Note: $c_{1}$ - conidial suspension in Coral modified liquid medium; $c_{2}$ - conidial suspension added with $1 \%$ glycerol; $c_{3}$ - conidial suspension added with $1 \%$ glycerol; $1 \%$ canola oil; $\mathrm{c}_{4}$ - conidial suspension added with $1 \%$ glycerol; $1 \%$ canola oil and $0.5 \%$ clay.

Fig. 3. The viability of conidia after 6 days of treatment depending on the type of fungal formulation and variety

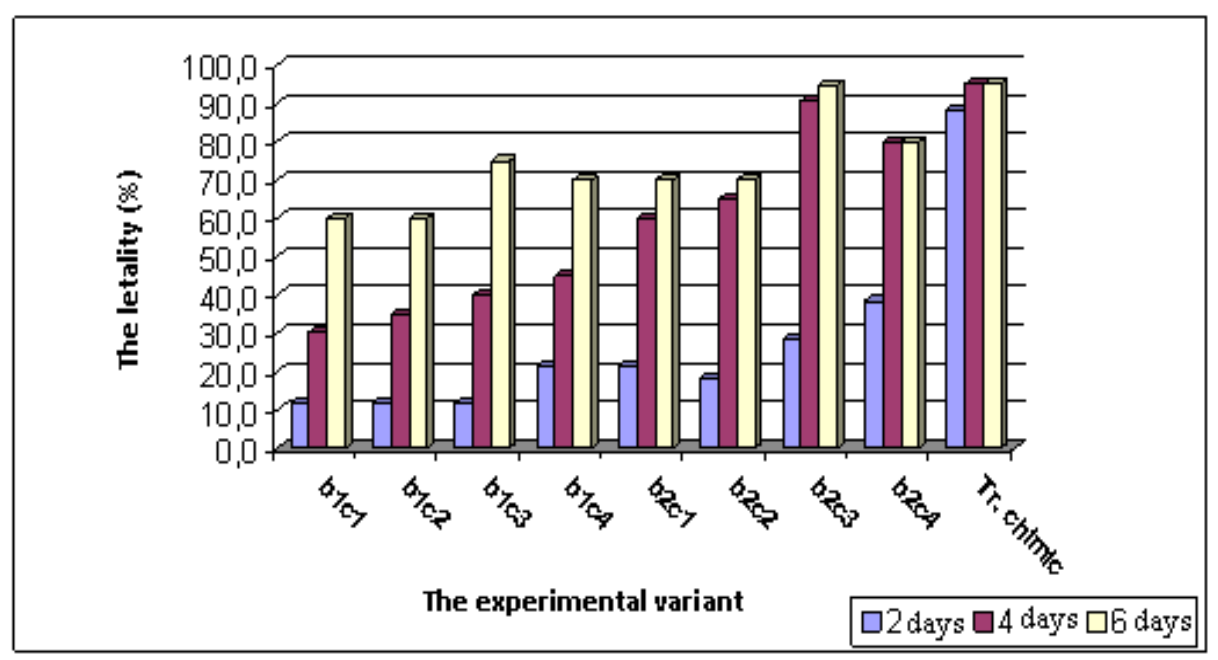

Note: b1 - $2.5 \times 10^{7}$ conidia/ml b2 - $3.2 \times 10^{9}$ conidia/ml; $\mathrm{c}_{1}$ - conidial suspension in Coral modified liquid medium; $\mathrm{c}_{2}-$ conidial suspension added with $1 \%$ glycerol; $\mathrm{c}_{3}$ - conidial suspension added with $1 \%$ glycerol; $1 \%$ canola oil; $\mathrm{c}_{4}$ - conidial suspension added with $1 \%$ glycerol; $1 \%$ canola oil and $0.5 \%$ clay.

Fig. 4. Insecticidal activity of the bioproducts during a week 
Our data do not contradict those obtained by Daoust and Pereira, (1986), which showed a persistence of the insecticidal activity of Beauveria bassiana conidia on leaves around a week. The treatments were carried out under exposure to sunlight with full protection, with partial protection and without protection. In terms of total exposure to sunlight, the viability of conidia was reduced at half in 1-2 days and the insecticidal activity lasted up to 7 days. Conidia protected from sunlight survived much longer, lasting insecticidal activity of approximately 3 weeks.

Similar results were obtained Sabbah et al., 2008, in terms of applying treatments with a bioinsecticid based on Beauveria bassiana in order to protect strawberries crops against Lygus lineolaris.

\section{CONCLUSION}

The formulations based on Beauveria bassiana caused a gradual reduction of populations of phylloxera, while the chemical treatment acted more intense and rapid.

Conidia of Beauveria bassiana can persist and infest the larvae and adults of phylloxera for at least 6 days. The repeated application of bioinsecticides based on Beauveria bassiana, every 6 days, can cause a significant decrease in the phylloxera population and can replace, partial or total, the chemical treatments.

\section{REFERENCES}

1. AbbotWS (1925). A method of computing the effectiveness of an insecticide. Journal of Economic Entomology, 18: $265-267$.

2. Daoust RA and Pereira RM (1986). Stability of entomopathogenic fungi Beauveria bassiana and Metarhizium anisopliae on beetle-attracting tubers and cowpea foliage in Brazil. Environ. Entomol., 15:12371243.

3. Dara SK, Mcguire MR, Kaya HK( 2007). Isolation and evaluation of beauveria bassiana (deuteromycotina hyphomycetes) for the suppression of glassy-winged sharpshooter, homalodisca coagula ta (homoptera cicadellidae). Journal of Entomological Science. 42: 56-65.

4. Feng MG, Poprawski TJ, Khachatourians GG (1994). Production, formulation and application of the entomopathogenic fungus Beauveria bassiana for insect control: Current status. Biocontrol Science and Technology 4: 3-34.

5. Liu H et Bauer LS (2008). Microbial control of emerald ash borer, Agrilus planipennis (Coleoptera: Buprestidae) with Beauveria bassiana strain GHA: Greenhouse and field trials Biological control. 45: 124-132.

6. Lomer CJ, Prior C and Kooyman C (1997). Developpment of Metarhizium sp. for the control of grasshoppers and locusts. In: Goettel MS, Johnson DL, editors. Microbial Control of Grasshoppers and Locusts. Memoirs of the Entomological Society of Canada 171, 265-286.

7. McGuire M., Leland LE (2006). Field trials of Beauveria bassiana against Lygus spp. in California and Mississippi. National Cotton Council Beltwide Cotton Conference. p. 1389-1392.

8. Nguyen N, Christian B, Hans-Michael P et Gisbert Z (2007). Laboratory investigations on the potential of entomopathogenic fungi for biocontrol of Helicoverpa armigera (Lepidoptera: Noctuidae) larvae and pupae. BiocontroJ Science and Technology. 17: 853-864.

9. Sabbahi R, Merzollki A et Guertin C (2008). Efficacy of Beauveria bassiana (Bals.) Vuill. against the tarnished plant bug, Lygus Iineolaris L., in strawberries. Journal of Applied Entomology. Volume 132, Issue 2: 124 - 134.

10. Todorova SI, Côté JC et Coderre D (1996). Evaluation of the effects of two Beauveria bassiana (Balsamo) vuillemin srtains on the development of Coleomegilla macuiatae lengi Timberlake (col, Coccinellidae), Journal of Applied Entomology, 120: 159-163.

11. Todorova SI, Coderre D, Côté JC et Vincent C (2002). Screening of Beauveria bassiana (Hyphomycetes) isolates against Choristoneura rrosaceana (Lepidoptera: Tortricidae). Cand. Entomol., 134: 77-84. 